\title{
Alcohol and the Eye
}

\author{
Saeed Karimi ${ }^{1,2}$, MD; Amir Arabi ${ }^{1,2}$, MD, MPH; Toktam Shahraki ${ }^{1,2}$, MD \\ ${ }^{1}$ Ophthalmic Research Center, Research Institute for Ophthalmology and Vision Science, Shahid Beheshti University of Medical \\ Sciences, Tehran, Iran \\ ${ }^{2}$ Department of Ophthalmology, Torfeh Hospital, Shahid Beheshti University of Medical Sciences, Tehran, Iran \\ ORCID: \\ Saeed Karimi: http://orcid.org/0000-0002-3231-8414 \\ Amir Arabi: http://orcid.org/0000-0002-6523-7733
}

\section{Abstract}

In this article, we present a review of ocular conditions related to alcohol consumption. A search of the literature published from 1952 to March 2020 was performed. The titles and abstracts were screened and the eligible studies were selected. PubMed, ISI Web of Knowledge database, Scopus, Embase, and the Cochrane Library were searched. We categorized the relationship between alcohol intake and ocular conditions by the type of ocular exposure to alcohol. Accordingly, ocular findings following acute alcohol intoxication, optic neuropathy following methanol toxicity, congenital conditions related to maternal alcohol consumption, and ocular disease related to chronic alcoholism are discussed. The main feature of alcohol intoxication in the eye is abnormal eye movement. Acute optic neuropathy secondary to methyl alcohol consumption is a serious ocular disease with permanent vision loss or scotoma. Prenatal exposure to ethanol may end in fetal alcohol spectrum disease, where ocular findings are a constant component. The association between chronic alcohol consumption and increased risks of cataract, age-related macular degeneration, diabetic retinopathy, different types of optic neuropathy, impairment of visual quality, retinal vascular disease, and ocular surface disease has also been reported. Along with detrimental medical and social effects, the role of alcohol consumption in different ocular conditions should be considered, as alcohol-induced visual disturbances may contribute to the heavy burden of alcohol abuse on the healthcare system and overall quality of life.

Keywords: Alcohol; Cornea; Dry Eye; Ethanol; Ethyl Alcohol; Eye; Fetal Alcohol; Glaucoma; Macular Degeneration; Methanol; Optic Neuropathy; Retinopathy; Teratogenicity

J Ophthalmic Vis Res 2021; 16 (2): 260-270

\section{INTRODUCTION}

As a potentially modifiable risk factor for many disorders, the importance of alcohol consumption

Correspondence to:

Amir Arabi, MD. Ophthalmic Research Center, Research Institute for Ophthalmology and Vision Science, Shahid Beheshti University of Medical Sciences, No. 23, Boostan 9 St., Paidarfard St., Pasdaran Ave., Tehran 16666, Iran.

E-mail: amir_arab_91@yahoo.com

Received: 03-12-2019Ａccepted: 14-09-2020

\section{Access this article online}

Website: https://knepublishing.com/index.php/JOVR

DOI: 10.18502/jovr.v16i2.9089 has already been documented in a variety of medical fields. The question is whether alcohol consumption should be considered as a contributing factor of ocular diseases. Through a comprehensive review of the current literature, this article will discuss on some ocular conditions which have been reported to be associated with alcohol consumption. We have categorized the

This is an open access journal, and articles are distributed under the terms of the Creative Commons Attribution-NonCommercial-ShareAlike 4.0 License, which allows others to remix, tweak, and build upon the work non-commercially, as long as appropriate credit is given and the new creations are licensed under the identical terms.

How to cite this article: Karimi S, Arabi A, Shahraki T. Alcohol and the Eye. $\mathrm{J}$ Ophthalmic Vis Res 2021;16:260-270. 
topic as follows:

i. Alcohol intoxication and the eye

ii. Acute methyl alcohol optic neuropathy

iii. Alcohol and congenital ocular diseases

iv. Chronic alcoholism and the eye

Alcohol consumption refers to the intake of drinks containing ethyl alcohol. According to the definitions in the United States, approximately $14 \mathrm{~g}$ of pure alcohol in any type of drink is considered as a standard alcoholic drink. ${ }^{[1]}$ The containing beverage can be regular beer, malt liquor, table wine, or distilled spirits.

Various studies have classified alcohol consumption differently. Alcohol consumption may be called heavy or light drinking, based on the overall measurement of the history of alcohol consumption, or may be estimated based on the number of drinks consumed per day or week [Table 1]. ${ }^{[2,3]}$ The definition of heavy drinking varies in the literature. In this review, the concept of heavy drinking will be clarified through both quantitative and qualitative descriptions of daily alcohol consumption based on moderate or heavy alcohol abuse.

\section{METHOD}

Papers published from January 1952 to March 2020 was reviewed by searching ISI Web of Knowledge database, PubMed, Scopus, Embase, and the Cochrane Library. The following keywords were used: "alcohol consumption", "ethanol", "ethyl alcohol", "alcohol and the eye", "alcohol and cataract", "alcohol and glaucoma", "alcohol and diabetic retinopathy", "alcohol and retinal disease", "alcohol and dry eye", and "alcohol and age-related macular degeneration”. No language limitation was applied. Articles and meta-analyses that published information about oral alcohol consumption and ocular disease were selected through review of abstracts, references, and titles. A total of 106 studies were included. The first study was published in 1952, and the last in 2019.

\section{ALCOHOL INTOXICATION}

Intoxication means the effect of acute consumption of alcohol on different physiologic processes in the body. Not only following binge drinking, it can even happen following acute intake of light or moderate levels of alcohol. ${ }^{[4]}$ The main feature of alcohol intoxication refers to its effect on the central nervous system. However, change in visual functions have always been focused in ethanol intoxications. Ocular findings may be related to reduction of Gamma-aminobutyric acid (GABA) activity, which is a major inhibitory neurotransmitter in the brain. ${ }^{[5]}$ GABA has been found in different parts of the visual pathway, from retinal ganglion and bipolar cells to the lateral geniculate nucleus, superior colliculus, and the visual cortex. ${ }^{[6]}$ Visual disturbance secondary to alcohol intoxication may manifest by impaired color perception, ${ }^{[4]}$ decreased contrast sensitivity, ${ }^{[7]}$ or abnormal eye movements. ${ }^{[8-10]}$ Impairment of cognitive processing in CNS may cause subclinical alterations in the eye movements. These alterations may include a high latency for fixation, increased duration of fixations, and increased frequency of saccades. ${ }^{[1]}$ In a study on alcohol intoxication and its ocular findings, volunteers of alcohol and placebo condition were evaluated by eye tracker to record eye movements during completion of Visual Maze Test. ${ }^{[11]}$ Significant differences were reported in the first fixation latency, total task time, and number and duration of fixations and saccades.

\section{ACUTE METHYL ALCOHOL INTOXICATION}

Methanol is a toxic alcohol found in industrial agents. Methanol toxicity can occur via inhalation, ingestion, or transdermal absorption. It is absorbed via the gastrointestinal tract in less than 10 min. ${ }^{[12]}$ Methyl alcohol is metabolized to formic acid, which is known to be the main mediator of permanent neurologic damage following methanol intoxication. ${ }^{[13,14]}$

Methanol can lead to ocular damage through two independent pathways: retinal damage and optic neuropathy. The former pathway refers to the damage to Muller cells and photoreceptors. ${ }^{[15,16]}$ Inner segment lesions of retinal photoreceptors have been reported to appear following methanol ingestion, where rods seems to be more sensitive to this insult, compared to cones. ${ }^{[1]}$ However, methanol-induced acute optic neuropathy has been studied more widely, and is considered as the main ocular damage following methanol intoxication. Ocular symptoms may occur in half of the intoxicated patients, and they often develop after $6 \mathrm{hr}$ following methanol ingestion. ${ }^{[18]}$ It is 
Table 1. Types of alcohol consumptions according to "drinking patterns and their definitions alcohol research: current reviews" 1 .

Type of alcohol consumption

Definition

Low-risk drinking and alcohol use disorder No more than 3-4 drinks on any single day and no more than 7-14 drinks per week

Moderate alcohol consumption

Up to 1-2 drinks per day

Binge drinking

4-5 drinks in a 2-hr time frame

Heavy drinking

Binge drinking on each of 5 or more days in the past 30 days

manifested by blurry vision, visual hallucination, dense central scotoma, and decreased visual acuity. The main findings on examination include nystagmus, sluggish pupils, disc swelling, and optic disc hyperemia. ${ }^{[12,17,19]}$ Demyelination of the retrobulbar portion of the optic nerve is a histopathologic hallmark of the condition. ${ }^{[20]}$ Formic acid is believed to damage oxidative pathways through mitochondrial cytochrome $C$ oxidase inhibition, which primarily affect susceptible zones of circulation including central nervous system and optic nerve watershed areas. $^{[21,22]}$ In addition, interrupted axoplasmic conduction secondary to sodium-potassium adenosine triphosphatase inhibition causes axonal swelling in the optic nerve. ${ }^{[20]}$ Finally, increased production of reactive oxygen mediators results in neuronal lysis. ${ }^{[4,14]}$

Methyl alcohol intoxication is a life-threatening condition, where its acute optic neuropathy is of secondary concern. However, presence of ocular signs and symptoms may help to make an early diagnosis, thus providing opportunity for more timely therapeutic measures. Correction of metabolic acidosis, elimination of methanol from the blood using hemodialysis, and competitive inhibition of alcohol dehydrogenase by ethanol or fomepizole are the mainstays of treatment. ${ }^{[13]}$

Among the medications used for methanolinduced acute optic neuropathy, intravenous high-dose methylprednisolone may be beneficial in the visual recovery of these patients [Table 2]. Recently, intravenous erythropoietin (EPO) added to high-dose intravenous steroids have been postulated to be an effective combination therapy. ${ }^{[23]}$ In a study on the topic, 11 participants received intravenous EPO $(10,000$ IU twice a day) for three days as an adjuvant to methylprednisolone, while other 11 participants received methylprednisolone only. Both final BCVA and thickness of retinal nerve fiber layer were reported to be significantly better in the
EPO group. ${ }^{[23]}$ In a prospective, non-comparative case series on 32 eyes of 16 patients, ${ }^{[24]}$ one or two courses of intravenous EPO $(20,000$ units/day for three days) appeared to improve visual acuity in patients with methanol optic neuropathy. The Erythropoietin in Methanol Associated Optic Neuropathy (EPO-MAON) trial (ClinicalTrials.gov Identifier: NCT02376881) is designed as a randomized, controlled trial to assess the efficacy of 20,000 IU EPO IV infusion for three successive days in improvement of visual outcome after three months following the treatment.

\section{FETAL ALCOHOL SYNDROME AND THE EYE}

As markers of teratogenesis, presence of ocular findings are considered as a useful adjunct to the diagnosis of fetal alcohol syndrome (FAS). It is believed that eye diseases occur in over $90 \%$ of children with the FAS. ${ }^{[30]}$ Recently, it has been postulated that patients with fully developed FAS present the highest rate of ocular findings. ${ }^{[31]}$

Alcohol has been shown to cause ocular defects by affecting expression of some transcription factors such as Pax6 and Otx2, ${ }^{[32-34]}$ retinoic acid signaling, ${ }^{[35-37]}$ and reactive agents of oxygen and nitrogen signaling. ${ }^{[38,39]}$ Furthermore, Hug et al reported abnormal retinal function according to abnormal electroretinograms in 10 FAS patients. ${ }^{[40]}$ Short palpebral fissures, epicanthus, ocular hypertelorism, coloboma, strabismus, blepharoptosis, microphthalmia, and abnormalities of the fundus are ocular manifestations of FAS. ${ }^{[41]}$ Also, some case reports of lens opacity associated with FAS have been published. ${ }^{[42]}$ The most frequent findings of the posterior segment are optic disc hypoplasia and tortuosity of the retinal vasculature. ${ }^{[43,44]}$ In the Swedish cohort of children with FAS, the prevalence of optic nerve hypoplasia and vascular tortuosity was reported to be $48 \%$ and $49 \%$, respectively. ${ }^{[45]}$ 
Table 2. A summary of studies performed on the efficacy of intravenous erythropoietin and high-dose corticosteroid as a medical treatment for methanol toxicity.

\begin{tabular}{|c|c|c|c|c|c|}
\hline Study & Year & Type of study & $\begin{array}{l}\text { Number of } \\
\text { patients }\end{array}$ & Treatment protocol & The main outcome \\
\hline Pakdel et al ${ }^{[24]}$ & 2018 & Non-comparative case series & 16 & $\begin{array}{l}\text { Intravenous recombinant } \\
\text { human EPO consisted of } \\
20,000 \text { units/day for three } \\
\text { successive days }\end{array}$ & $\begin{array}{l}\text { BCVA significantly } \\
\text { increased in the last } \\
\text { follow-up examination }\end{array}$ \\
\hline Pakravan et al ${ }^{[23]}$ & 2016 & Comparative case series & 11 & $\begin{array}{l}\text { Intravenous recombinant } \\
\text { human EPO consisted of } \\
10,000 \text { IU twice a day for } \\
\text { three days as an adjuvant } \\
\text { to methylprednisolone }\end{array}$ & $\begin{array}{l}\text { The final BCVA was } \\
\text { significantly better in the } \\
\text { EPO group }\end{array}$ \\
\hline Yunard et al ${ }^{[25]}$ & 2016 & Case series & 19 & $\begin{array}{l}\text { Intravenous high-dose } \\
\text { methylprednisolone with or } \\
\text { without hemodialysis }\end{array}$ & $\begin{array}{l}73 \% \text { of the cases showed } \\
\text { VA improvement }\end{array}$ \\
\hline Sharma et al ${ }^{[26]}$ & 2012 & Case series & 4 & $\begin{array}{l}500 \text { mg } \\
\text { methylprednisolone twice a } \\
\text { day for } 3 \text { days; followed by } \\
\text { oral prednisolone } 1 \\
\text { mg/kg/day for } 11 \text { days }\end{array}$ & $\begin{array}{l}100 \% \text { of the cases showed } \\
\text { VA improvement }\end{array}$ \\
\hline Abrishami et al ${ }^{[27]}$ & 2011 & Case series & 6 & $\begin{array}{l}250 \mathrm{mg} \text { intravenous methyl } \\
\text { prednisolone every } 6 \mathrm{hr} \text { for } \\
4 \text { days; followed by oral } \\
\text { prednisolone } 1 \mathrm{mg} / \mathrm{kg} / \mathrm{day} \\
\text { for } 10 \text { days }\end{array}$ & $\begin{array}{l}100 \% \text { of the cases showed } \\
\text { VA improvement }\end{array}$ \\
\hline Triningrat et al ${ }^{[28]}$ & 2010 & Retrospective descriptive study & 16 & $\begin{array}{l}\text { Hemodialysis and } \\
\text { intravenous } \\
\text { methylprednisolone } 1000 \\
\text { mg/day for three days, } \\
\text { followed by oral } \\
\text { prednisone } 1 \mathrm{mg} / \mathrm{kg} / \text { day for } \\
11 \text { days }\end{array}$ & $\begin{array}{l}100 \% \text { of the cases showed } \\
\text { VA improvement }\end{array}$ \\
\hline Shukla et al ${ }^{[29]}$ & 2006 & Case series & 17 & $\begin{array}{l}\text { Intravenous } \\
\text { methylprednisolone } 1000 \\
\text { mg/day for three days }\end{array}$ & $\begin{array}{l}82 \% \text { of the cases showed } \\
\text { VA improvement }\end{array}$ \\
\hline
\end{tabular}

BCVA, best corrected visual acuity; EPO, erythropoietin; VA, visual acuity

The high prevalence of ocular involvement in FAS has led the researchers to present a diagnostic tool called "4-Digit Eye Diagnostic Code." This tool uses four main ocular manifestation of FAS, including visual acuity, refraction, strabismus, and structural abnormalities, to present a diagnostic help and guideline for follow-up examinations in FAS patients. ${ }^{[31]}$ Not only for diagnosis, ocular examination permits appropriate management of ocular disease in FAS, which prevents visual loss. ${ }^{[41]}$

More recently, modulation of ion channel has been studied for their potential ability in reducing ocular defects in FAS. ${ }^{[46]}$ In animal models, blue light-mediated hyperpolarization of membranes through ChR2D156A channels rescued ethanolinduced eye structural defects. ${ }^{[46]}$

\section{CHRONIC ALCOHOLISM AND THE EYE}

\section{Age-related Macular Degeneration (AMD)}

AMD is a frequent cause of blindness among the elderly in developed countries. ${ }^{[47,48]}$ Numerous epidemiological studies have supported the probable link between alcohol consumption and $A M D,{ }^{[2]}$ however, the pathophysiological mechanisms remain unclear. Alcohol is considered as a neurotoxin that causes brain damage via oxidative pathways. Hence, the retina might be similarly affected. ${ }^{[49,50]}$ Additionally, increased oxidant stress associated with excess alcohol consumption has caused tissue damage in different organs of animal 
models. ${ }^{[51,52]}$ Furthermore, due to poor nutrition in heavy drinkers, decreased intake levels of carotene and antioxidants are more likely to occur. ${ }^{[53,54]}$ Some protective nutrients against AMD, such as zinc and vitamin, are also lower in heavy drinkers compared to nondrinkers. ${ }^{[55,56]}$ Finally, alcohol has been related to formation of new vessels and progression of choroidal neovascularization in animal studies. $^{[57]}$

A meta-analysis indicated that consumption of $\geq 30 \mathrm{~g} /$ day of alcohol was correlated to a higher risk of early AMD by $47-67 \% .{ }^{[58]}$ Additionally, some evidence showed that the type of alcohol may be relevant. In the Beaver Dam Eye Study (BDES), drinking of neither wine nor liquor was associated with early or late age-related maculopathy, while beer drinking was related to retinal drusen in men. ${ }^{[59,60]}$ In the Melbourne Collaborative Cohort Study, the largest and most recent prospective study on 20,963 participants since 2003 to 2007, consuming more than 20 $\mathrm{g}$ of alcohol per day increased the incidence of early AMD by approximately $20 \%$ in both sexes. ${ }^{[61]}$ This study also revealed that not only high levels but also social or moderate levels of alcohol consumption increase the risk of early AMD. ${ }^{[61]}$

\section{Diabetic Retinopathy (DR)}

Results of studies on the relationship between alcohol consumption and incidence of diabetic retinopathy (DR) have been contradictory. Literature reports that the associations are limited and findings are confusing. Among the initial studies in this field, a prospective study revealed that patients with diabetes who consumed more than $31 \mathrm{~g}$ of alcohol per day had a higher risk of developing DR compared to the non- to light drinkers. ${ }^{[62]}$ In the following studies, no correlation between baseline alcohol intake and the progression of DR was evident over more than four years. ${ }^{[63,64]}$ In a recent meta-analysis of 15 observational studies, alcohol intake was not associated with an increased risk of DR. ${ }^{[65]}$ In the subgroup analysis, no significant correlations were found between different stages of DR and various alcohol consumption groups. The main limitation of this meta-analysis was lower number of cohort studies included.

\section{Retinal Vein Occlusion (RVO)}

Hyperviscosity and severe dehydration resulting from a high alcohol intake has been linked to central retinal vein occlusion (RVO) in young patients. ${ }^{[66]}$

In the Eye Disease Case-Control Study, moderate alcohol consumption was reported to be protective, as it was linked to lower odds of RVO. ${ }^{[67]}$ However, other studies, such as the BDES, revealed no such association between alcohol consumption and RVO. ${ }^{[68]}$

\section{Other Retinal Conditions}

Alcohol is a known risk factor for central serous chorioretinopathy (CSCR). ${ }^{[69]}$ It may contribute to nitric oxide-related abnormalities of autoregulation of the choroidal blood vessels. ${ }^{[70]}$ Altered regulation of the choroidal blood flow can increase the permeability of the vasculature as well as accumulation and leakage of the fluid. Moreover, in a report of alcoholic liver disease and bilateral multifocal CSCR, the authors postulated that endstage liver disease secondary to alcoholism could be the etiology of CSCR. ${ }^{\text {[1] }}$

In BDES, drinking more than four drinks/day of alcohol was associated with asteroid hyalosis. ${ }^{[72]}$

Adolescence is a period of important neurological development, and alcohol exposure in this period may cause some visual defects, particularly defects of color vision, which is more sensitive to neurotoxicants. ${ }^{[4]}$ The visual scotopic performance also worsens with heavy alcohol consumption. ${ }^{[73]}$ In a study on the topic, both the retinal image quality and visual performance under low-scotopic conditions were worsened after acute alcohol consumption. Increased pupil size and tear film disturbances were presented as the etiological factors of decreased optical quality. ${ }^{[73]}$

\section{Alcohol-related Optic Neuropathy}

Toxic/nutritional optic neuropathy secondary to chronic alcohol consumption is characterized by central or cecocentral scotoma due to papillomacular bundle damage, associated with color vision defects. ${ }^{[74]}$ A detailed history and ocular examination, color vision and visual field tests, and laboratory investigations for serum B12 and folate levels are required to obtain the 
diagnosis. ${ }^{[18]}$ The management includes reduction or cessation of alcohol intake, and vitamin B12 and folate supplementation. ${ }^{\text {[75] }}$

\section{Glaucoma}

Results of the Framingham Eye Study were conflicting, as they suggested that high alcohol consumption might be associated with glaucoma. ${ }^{[76]}$ In the Long Island Glaucoma CaseControl Study, ${ }^{[77]}$ alcohol consumption was more frequent in patients with higher intraocular pressure (IOP) compared to the controls. In a hospital-based study in Japan, men with alcohol consumption showed a high risk of elevated IOP. ${ }^{[78]}$ In this study, 569 men and women participated, where alcohol consumption had a significantly positive association with the IOP in men. Interestingly, women did not show this association. A similar sex-related difference was reported in the Barbados Eye Study: current alcohol consumption was positively related to IOP in men. Notably, the Barbados Study included black patients without glaucoma, and as a superiority over Framingham Study, the results were reported after controlling for obesity and hypertension. ${ }^{[79]}$ Similar results were reported in the studies of the Chinese population: Chinese men $>65$ years who were current alcohol consumers had higher IOP compared to female consumers. ${ }^{[80]}$ It is notable that in the latter study, non-contact tonometry was used to measure the IOP.

On the other hand, acute alcohol ingestion reportedly lowers IOP in both healthy and glaucomatous eyes. ${ }^{[81,82]}$ Both hyperosmotic effect and suppression of vasopressin by ethanol in the blood reduces blood flow and net water transport into the eye. ${ }^{[83]}$ Moreover, an inhibitory effect on the secretory cells in the ciliary process is reportedly related to alcohol intake. ${ }^{[84]}$ Although alcohol may decrease the blood flow of the anteriorly located ciliary body, posterior structures, such as the optic nerve, may receive more blood when alcohol is present in the circulation. This mechanism can be protective against the development of primary open-angle glaucoma (POAG). ${ }^{[85]}$ Along with these basic evidences, a subset of case-control studies reported the protective effects of alcohol consumption against the incidence of POAG and elevated IOP. ${ }^{[86,87]}$ In a study on 100 age- and sex-matched ocular hypertensive patients and 100 ocular normotensive patients, absence of liquor consumption was significantly associated with the presence of ocular hypertension. ${ }^{[87]}$

Between these two extremes of converse results, various epidemiological studies reported no association between alcohol and IOP elevation or glaucoma. ${ }^{[88]}$

The only report on the longitudinal correlation of IOP and alcohol consumption was delivered by the Barbados Eye Study, ${ }^{[89]}$ in which alcohol consumption at baseline was not associated with a higher four-year risk of elevated IOP. ${ }^{[89]}$ Additionally, in a large prospective study on 856 participants including both sexes, chronic alcohol intake $<30 \mathrm{~g} / \mathrm{day}$ did not influence the risk of POAG. ${ }^{[90]}$ Accordingly, the relationship between alcohol consumption and the risk of glaucoma requires a more prospective investigation with detailed assessments on alcohol use.

\section{Alcohol and Cataract}

A recent systematic review and meta-analysis revealed that heavy alcohol consumption significantly increased the risk of age-related cataract. $^{[91]}$ In this meta-analysis which was performed on 10 studies, the correlation of moderate alcohol consumption and senile cataract were marginally non-significant. Heavy alcohol consumption could produce free radicals in the liver. Transmission of the products to the lens may lead to aggregation of lens proteins, leading to cataract formation. ${ }^{[91,92]}$ Acute alcohol exposure increases intracellular lens calcium levels through inhibition of the calcium pumps on lens fibers. ${ }^{[93]}$ This disturbance in calcium homeostasis may lead to cataract formation.

\section{Alcohol and ocular surface disease}

Although topical administration of ethanol is a known cause of keratopathy and has been used for epithelial cell removal in different ocular surgeries, ${ }^{[94,95]}$ controversial opinions on the association between oral alcohol and ocular surface disease have been published. In a casecontrol study, $0.75 \mathrm{~g} / \mathrm{kg}$ of oral ethanol was administered to 10 volunteer men at 8 pm. ${ }^{[96]}$ Presence of ethanol in tears, tear osmolarity, Schirmer test, and tear break-up time (TBUT) were evaluated at midnight and the next morning. 
Table 3. Some ocular conditions related to alcohol consumption

Type of alcohol consumption

Acute alcohol intoxication

Acute methanol optic neuropathy

Alcohol teratogenicity

Chronic alcoholism

\section{Ocular findings}

Abnormal eye movements, altered color perception, decreased contrast sensitivity

Optic disc edema, retinal ganglion cell damages, permanent scotoma or vision loss

Short palpebral fissures, epicanthus, ocular hypertelorism, coloboma, strabismus, blepharoptosis, cataract, microphthalmia, hypoplasia of the optic nerve, tortuosity of the retinal vessels

Anterior segment
Cataract
Dry eye syndrome
Corneal epitheliopathy
Intraocular pressure
Primary open angle glaucoma
Optic nerve
Alcohol-induced optic neuropathy
Retina and choroid
Age-related macular degeneration
Diabetic retinopathy
Retinal vein occlusion
Central serous chorioretinopathy
Functional retinal disease
Asteroid hyalosis

Ethanol was detected in tears at midnight, while it was undetectable in the tear samples collected next morning. The authors reported that the presence of alcohol in tears was associated with increased tear osmolarity, decreased TBUT, and staining of ocular surface with fluorescein. Schirmer test and corneal sensitivity showed no change. In other publications, Chia et al ${ }^{[97]}$ argued the protective role of alcohol in the development of dry eye syndrome (DES), while Galor et al $^{[98]}$ showed that drinking increases the risk of DES. The BDES reported a higher rate of DES symptoms in individuals with a history of heavy alcohol consumption. ${ }^{[99]}$ A comparative case-control study on men with alcohol consumption more than four drinks/day reported decreased Schirmer test result and TBUT, in addition to changed impression cytology of the conjunctiva. ${ }^{[100]}$ Some other researchers believed that DES may have no association with alcohol consumption. [101-103]

The results of a recent meta-analysis involving nine cross-sectional and one case-control studies indicated that alcohol consumption could increase the risk of DES, irrespective of age and sex. ${ }^{[104]}$ Tear hyperosmolarity following alcohol consumption has been detected after heavy drinking. ${ }^{[73,105]}$
Moreover, ethanol induces the expression of interleukin-1, interleukin-6, and interleukin-8 in the ocular surface cells. ${ }^{[106]}$ As an additional mechanism, chronic alcoholism can induce vitamin A deficiency by reducing retinol in the liver. Absence of vitamin A causes increased epidermal keratinization through loss of the goblet cells from the cornea and conjunctiva, which is a major pathogenesis of DES. ${ }^{[107,108]}$

\section{DISCUSSION}

Many pathophysiological aspects of the deteriorating effects of alcohol consumption on ocular structures have been demonstrated, however, additional well-designed studies are required for a definite conclusion. According to the present medical literature, along with harmful effects on many other organs of the body, alcohol consumption may damage ocular tissues, from the cornea and conjunctiva to the retina and optic nerve. Among them, alcohol teratogenicity and alcohol-related optic neuropathies are more definite and seem to be the most serious ocular conditions related to alcohol consumption [Table 3]. 
Ophthalmologists should consider alcohol consumption as a modifiable risk factor for ocular disease.

Future direction on clinical aspects of the topic may be as follows:

i. How to reduce the adverse effects of prenatal alcohol exposure in pregnant alcohol drinkers?

ii. How to optimize the management of acute methanol toxicity and its optic neuropathy to preserve a higher level of vision and visual function?

iii. How oral ethanol can expose heavy drinkers to ocular surface disease?

\section{REFERENCES}

1. Alcohol Research: Current Reviews Editorial Staff. Drinking Patterns and Their Definitions. Alcohol Res. 2018;39(1):1718.

2. Wang S, Wang JJ, Wong TY. Alcohol and eye diseases. Surv Ophthalmol 2008;53:512-525.

3. Weih LM, Mukesh BN, McCarty CA, Taylor HR. Association of demographic, familial, medical, and ocular factors with intraocular pressure. Arch Ophthalmol 2001;119:875-880.

4. Brasil A, Castro AJ, Martins IC, Lacerda EM, Souza GS, Herculano A, et al. Colour Vision impairment in young alcohol consumers. PloS ONE 2015;10:e0140169.

5. Lobo IA, Harris RA. GABA(A) receptors and alcohol. Pharmacol Biochem Behav 2008;90:90-94.

6. Xiao $\mathrm{C}$, Ye JH. Ethanol dually modulates GABAergic synaptic transmission onto dopaminergic neurons in ventral tegmental area: role of mu-opioid receptors. Neuroscience 2008;153:240-248.

7. Galdino M, Mendes, Mendes-Santos L, Vieira J, De Bustamante Simas $M$, Santos N. Visual perception of radial sine-wave grating after the alcohol consumption. Psicologia USP 2010;22:99-115.

8. Marinkovic K, Rickenbacher E, Azma S, Artsy E, Lee AKC. Effects of acute alcohol intoxication on saccadic conflict and error processing. Psychopharmacology 2013;230:487-497.

9. Abroms B, Gottlob L, Fillmore M. Alcohol effects on inhibitory control of attention: Distinguishing between intentional and automatic mechanisms. Psychopharmacology 2006;188:324-334.

10. Schmitt KU, Lanz C, Muser MH, Walz F, Schwarz U. Saccadic eye movements after low-dose oral alcohol exposure. J Forensic Leg Med 2013;20:870-874.

11. Silva JBS, Cristino ED, Almeida NL, Medeiros PCB, Santos NAD. Effects of acute alcohol ingestion on eye movements and cognition: a double-blind, placebo-controlled study. PloS ONE 2017;12:e0186061-e0186061.

12. Ashurst JV, Nappe TM. Methanol toxicity. In: StatPearls. Treasure Island, FL: StatPearls Publishing LLC.; 2019.

13. Barceloux DG, Bond GR, Krenzelok EP, Cooper H, Vale JA. American Academy of Clinical Toxicology practice guidelines on the treatment of methanol poisoning. $J$ Toxicol Clin Toxicol 2002;40:415-446.
14. Givens M, Kalbfleisch K, Bryson S. Comparison of methanol exposure routes reported to Texas poison control centers. West J Emerg Med 2008;9:150-153.

15. Martin-Amat G, McMartin KE, Hayreh SS, Hayreh MS, Tephly TR. Methanol poisoning: ocular toxicity produced by formate. Toxicol Appl Pharmacol 1978;45:201-208.

16. Kraut JA, Kurtz I. Toxic alcohol ingestions: clinical features, diagnosis, and management. Clin J Am Soc Nephrol 2008;3:208.

17. Baumbach GL, Cancilla PA, Martin-Amat G, Tephly TR, McMartin KE, Makar AB, et al. Methyl alcohol poisoning. IV. Alterations of the morphological findings of the retina and optic nerve. Arch Ophthalmol 1977;95:1859-1865.

18. Sharma P, Sharma R. Toxic optic neuropathy. Indian J Ophthalmol 2011;59:137-141.

19. Al Aseri Z, Altamimi S. Keeping a high index of suspicion: lessons learned in the management of methanol ingestion. BMJ Case Rep 2009;2009.

20. Naeser P. Optic nerve involvement in a case of methanol poisoning. Br J Ophthalmol 1988;72:778-781.

21. Benton CD Jr, Calhoun FP Jr. The ocular effects of methyl alcohol poisoning: report of a catastrophe involving three hundred and twenty persons. Trans Am Acad Ophthalmol Otolaryngol 1952;56:875-885

22. Rotenstreich $\mathrm{Y}$, Assia El, Kesler A. Late treatment of methanol blindness. Br J Ophthalmol 1997;81:416-417.

23. Pakravan $M$, Esfandiari $H$, Sanjari $N$, Ghahari $E$. Erythropoietin as an adjunctive treatment for methanolinduced toxic optic neuropathy. Am J Drug Alcohol Abus 2016;42:633-639.

24. Pakdel F, Sanjari MS, Naderi A, Pirmarzdashti N, Haghighi A, Kashkouli MB. Erythropoietin in treatment of methanol optic neuropathy. J Neuro-Ophthalmol 2018;38:167-171.

25. Yunard A, Nusanti S, Sidik M. Methanol toxic optic neuropathy (characteristic and evaluation of therapy). Ophthalmol India 2016;42:38-44.

26. Sharma R, Marasini S, Sharma AK, Shrestha JK, Nepal BP. Methanol poisoning: ocular and neurological manifestations. Optom Vis Sci 2012;89:178-182.

27. Abrishami $M$, Khalifeh $M$, Shoayb $M$, Abrishami M. Therapeutic effects of high-dose intravenous prednisolone in methanol-induced toxic optic neuropathy. J Ocul Pharmacol Ther 2011;27:261-263.

28. Triningrat AAMP,Rahayu NMK,Manuabal BP. Visual acuity of methanol intoxicated patients before and after hemodialysis, methyprednisolone and prednisone therapy. JOI 2010;7:129-132.

29. Shukla M, Shikoh I, Saleem A. Intravenous methylprednisolone could salvage vision in methyl alcohol poisoning. Indian J Ophthalmol. 2006 Mar;54(1):68-69.

30. Brennan D, Giles S. Ocular involvement in fetal alcohol spectrum disorder: a review. Current pharmaceutical design. 2014;20.

31. Aring EM, Landgren M, Svensson L, Gronlund MA. An eye diagnostic code for evaluation of ophthalmological abnormalities in fetal alcohol syndrome disorders. Invest Ophthalmol Vis Sci 2015;56:1378-1378.

32. Peng $\mathrm{Y}$, Yang PH, Ng SS, Wong OG, Liu J, He ML, et al. A critical role of Pax6 in alcohol-induced fetal microcephaly. Neurobiol Dis 2004;16:370-376. 
33. Yelin R, Kot H, Yelin D, Fainsod A. Early molecular effects of ethanol during vertebrate embryogenesis. Differentiation 2007;75:393-403.

34. Yelin R, Schyr RB, Kot H, Zins S, Frumkin A, Pillemer G, et al. Ethanol exposure affects gene expression in the embryonic organizer and reduces retinoic acid levels. Dev Biol 2005;279:193-204.

35. Shukrun N, Shabtai Y, Pillemer-Amdur G, Fainsod A. Retinoic acid signaling reduction recapitulates the effects of alcohol on embryo size. Genesis 2019;57:e23284.

36. Shabtai Y, Fainsod A. Competition between ethanol clearance and retinoic acid biosynthesis in the induction of Fetal Alcohol Syndrome. Biochem Cell Biol 2017;96(2):148160.

37. Kot-Leibovich H, Fainsod A. Ethanol induces embryonic malformations by competing for retinaldehyde dehydrogenase activity during vertebrate gastrulation. Dis Model Mech 2009;2:295-305.

38. Peng $\mathrm{Y}$, Yang $\mathrm{P}-\mathrm{H}, \mathrm{Ng} \mathrm{S}$, Lum $\mathrm{C}$, Kung $\mathrm{H}-\mathrm{F}$, Lin $\mathrm{M}$. Protection of Xenopus laevis embryos against alcoholinduced delayed gut maturation and growth retardation by peroxiredoxin 5 and catalase. J Mol Biol 2004;340:819827.

39. Peng $\mathrm{Y}$, Yang $\mathrm{PH}$, Guo $\mathrm{Y}, \mathrm{Ng} \mathrm{SS}$, Liu J, Fung PC, et al. Catalase and peroxiredoxin 5 protect Xenopus embryos against alcohol-induced ocular anomalies. Invest Ophthalmol Vis Sci 2004;45:23-29.

40. Hug TE, Fitzgerald KM, Cibis GW. Clinical and electroretinographic findings in fetal alcohol syndrome. $J$ AAPOS 2000;4:200-204.

41. Abdelrahman A, Conn R. Eye abnormalities in fetal alcohol syndrome. Ulster Med J 2009;78:164-165.

42. Peragallo J, Biousse V, Newman NJ. Ocular manifestations of drug and alcohol abuse. Curr Opin Ophthalmol 2013;24:566-573.

43. Ribeiro IM, Vale PJ, Tenedorio PA, Rodrigues PA, Bilhoto MA, Pereira HC. Ocular manifestations in fetal alcohol syndrome. Eur J Ophthalmol 2007;17:104-109.

44. Flanigan EY, Aros S, Bueno MF, Conley M, Troendle JF, Cassorla F, Mills JL, et al. Eye malformations in children with heavy alcohol exposure in utero. J Pediatr 2008;153:391-395.

45. Strömland K. Ocular involvement in the fetal alcohol syndrome. Surv Ophthalmol 1987;31:277-284.

46. Pai V, Adams D. Preventing Ethanol-induced brain and eye morphology defects using optogenetics. Bioelectricity 2019;1:260-272.

47. Klein R, Klein BE, Linton KL. Prevalence of age-related maculopathy. The Beaver Dam Eye Study. Ophthalmology 1992;99:933-943.

48. Friedman DS, O'Colmain BJ, Muñoz B, Tomany SC, McCarty C, de Jong PT, et al. Prevalence of agerelated macular degeneration in the United States. Arch Ophthalmol 2004;122:564-572.

49. Agar E, Demir S, Amanvermez R, Bosnak M, Ayyildiz M, Celik $C$. The effects of ethanol consumption on the lipid peroxidation and glutathione levels in the right and left brains of rats. Int J Neurosci 2003;113:1643-1652.

50. Cederbaum Al. Role of lipid peroxidation and oxidative stress in alcohol toxicity. Free Radic Biol Med 1989;7:537539.
51. Rikans LE, Gonzalez LP. Antioxidant protection systems of rat lung after chronic ethanol inhalation. Alcohol Clin Exp Res 1990;14:872-877.

52. Rosenblum ER, Gavaler JS, Van Thiel DH. Lipid peroxidation: a mechanism for alcohol-induced testicular injury. Free Radic Biol Med 1989;7:569-577.

53. Galan P, Viteri FE, Bertrais S, Czernichow S, Faure H, Arnaud J, et al. Serum concentrations of beta-carotene, vitamins $C$ and $E$, zinc and selenium are influenced by sex, age, diet, smoking status, alcohol consumption and corpulence in a general French adult population. Eur J Clin Nutr 2005;59:1181-1190.

54. Stryker WS, Kaplan LA, Stein EA, Stampfer MJ, Sober A, Willett WC. The relation of diet, cigarette smoking, and alcohol consumption to plasma beta-carotene and alphatocopherol levels. Am J Epidemiol 1988;127:283-296.

55. Manari AP, Preedy VR, Peters TJ. Nutritional intake of hazardous drinkers and dependent alcoholics in the UK. Addict Biol 2003;8:201-210.

56. Bergheim I, Parlesak A, Dierks C, Bode JC, Bode C. Nutritional deficiencies in German middle-class male alcohol consumers: relation to dietary intake and severity of liver disease. Eur J Clin Nutr 2003;57:431-438.

57. Bora PS, Kaliappan S, Xu Q, Kumar S, Wang Y, Kaplan $\mathrm{HJ}$, et al. Alcohol linked to enhanced angiogenesis in rat model of choroidal neovascularization. FEBSJ 2006;273:1403-1414.

58. Chong EW, Kreis AJ, Wong TY, Simpson JA, Guymer RH. Alcohol consumption and the risk of age-related macular degeneration: a systematic review and meta-analysis. $\mathrm{Am}$ J Ophthalmol 2008;145:707-715.

59. Ritter LL, Klein R, Klein BE, Mares-Perlman JA, Jensen SC. Alcohol use and age-related maculopathy in the Beaver Dam Eye Study. Am J Ophthalmol 1995;120:190-196.

60. Moss SE, Klein R, Klein BE, Jensen SC, Meuer SM. Alcohol consumption and the 5-year incidence of age-related maculopathy: the Beaver Dam eye study. Ophthalmology 1998;105:789-794.

61. Adams MK, Chong EW, Williamson E, Aung KZ, Makeyeva GA, Giles GG, et al. 20/20-Alcohol and age-related macular degeneration: the Melbourne Collaborative Cohort Study. Am J Epidemiol 2012;176:289-298.

62. Young RJ, McCulloch DK, Prescott RJ, Clarke BF. Alcohol: another risk factor for diabetic retinopathy? $\mathrm{Br}$ Med $\mathrm{J}$ 1984;288:1035-1037.

63. Moss SE, Klein R, Klein BE. Alcohol consumption and the prevalence of diabetic retinopathy. Ophthalmology 1992;99:926-932.

64. Moss SE, Klein R, Klein BE. The association of alcohol consumption with the incidence and progression of diabetic retinopathy. Ophthalmology 1994;101:1962-1968.

65. Zhu W, Meng YF, Wu Y, Xu M, Lu J. Association of alcohol intake with risk of diabetic retinopathy: a meta-analysis of observational studies. Sci Rep 2017;7:4.

66. Francis PJ, Stanford MR, Graham EM. Dehydration is a risk factor for central retinal vein occlusion in young patients. Acta Ophthalmol. Scand 2003;81:415-416.

67. Sperduto RD, Hiller R, Chew E, Seigel D, Blair N, Burton $\mathrm{TC}$, et al. Risk factors for hemiretinal vein occlusion: comparison with risk factors for central and branch retinal vein occlusion: the eye disease case-control study. Ophthalmology 1998;105:765-771. 
68. Klein R, Klein BE, Moss SE, Meuer SM. The epidemiology of retinal vein occlusion: the Beaver Dam Eye Study. Trans Am Ophthalmol Soc 2000;98:133-141; discussion 141-133.

69. Liu B, Deng T, Zhang J. Risk factors for central serous chorioretinopathy: a systematic review and meta-analysis. Retina 2016;36:9-19.

70. Tittl MK, Spaide RF, Wong D, Pilotto E, Yannuzzi LA, Fisher $\mathrm{YL}$, et al. Systemic findings associated with central serous chorioretinopathy. Am J Ophthalmol 1999;128:63-68.

71. Gkotsi D, Gupta M, Lascaratos G, Syrogiannis A, Dhillon B. Alcoholic liver disease and bilateral multifocal central serous retinopathy: a case report. J Med Case Rep 2013;7:43.

72. Moss SE, Klein R, Klein BE. Asteroid hyalosis in a population: the Beaver Dam eye study. Am J Ophthalmol 2001;132:70-75.

73. Castro JJ, Pozo AM, Rubino M, Anera RG, Jimenez Del Barco L. Retinal-image quality and night-vision performance after alcohol consumption. J Ophthalmol 2014;2014:704823.

74. Kesler A, Pianka P. Toxic optic neuropathy. Curr Neurol Neurosci 2003;3:410-414.

75. Joseph S, Al-Ali S, Tripathi A. Tobacco-alcohol optic neuropathy. Is complete recovery possible? Oman J Ophthalmol 2014;7:50.

76. Kahn HA, Milton RC. Alternative definitions of open-angle glaucoma. Effect on prevalence and associations in the Framingham eye study. Arch Ophthalmol 1980;98:21722177.

77. Leske MC, Warheit-Roberts L, Wu SY. Open-angle glaucoma and ocular hypertension: the Long Island glaucoma case-control Study. Ophthalmic Epidemiol 1996;3:85-96.

78. Yoshida M, Ishikawa M, Kokaze A, et al. Association of lifestyle with intraocular pressure in middle-aged and older Japanese residents. Jpn J Ophthalmol 2003;47:191-198.

79. Wu SY, Leske MC. Associations with intraocular pressure in the Barbados Eye Study. Arch Ophthalmol 1997;115:1572-1576.

80. Lin HY, Hsu WM, Chou P, Liu CJ, Chou JC, Tsai SY, et al. Intraocular pressure measured with a noncontact tonometer in an elderly Chinese population: the Shihpai Eye Study. Arch Ophthalmol 2005;123:381-386.

81. Giurlani BP, Obie LG, Petersen CG, Presley DD. Alcohol and open angle glaucoma-influence on detection, IOP, BP/IOP ratios. J Am Optom Assoc 1978;49:409-416.

82. Buckingham T, Young R. The rise and fall of intra-ocular pressure: the influence of physiological factors. Ophthal Physl Opt 1986;6:95-99.

83. Houle RE, Grant WM. Alcohol, vasopressin, and intraocular pressure. Invest Ophthalmol 1967;6:145-154.

84. Leydhecker W, Krieglstein GK, Uhlich E. [Experimental investigations on the mode of action of alcoholic liquor on the intra-ocular pressure (author's transl)]. Klin Monatsbl Augenh 1978;173:75-79.

85. Kojima S, Sugiyama T, Kojima M, Azuma II, Ito S. Effect of the consumption of ethanol on the microcirculation of the human optic nerve head in the acute phase. Jpn J Ophthalmol 2000;44:318-319.

86. Fan BJ, Leung YF, Wang N, Lam SC, Liu Y, Tam OS, et al. Genetic and environmental risk factors for primary openangle glaucoma. Chin Med J 2004;117:706-710.
87. Seddon JM, Schwartz B, Flowerdew G. Case-control study of ocular hypertension. Arch Ophthalmol 1983;101:891894.

88. Al Owaifeer AM, Al Taisan AA. The role of diet in glaucoma: a review of the current evidence. Ophthalmol Ther 2018;7:19-31.

89. Nemesure B, Wu SY, Hennis A, Leske MC. Factors related to the 4-year risk of high intraocular pressure: the Barbados Eye Studies. Arch Ophthalmol 2003;121:856862.

90. Kang JH, Willett WC, Rosner BA, Hankinson SE, Pasquale LR. Prospective study of alcohol consumption and the risk of primary open-angle glaucoma. Ophthalmic Epidemiol 2007;14:141-147.

91. Gong Y, Feng K, Yan N, Xu Y, Pan CW. Different amounts of alcohol consumption and cataract: a meta-analysis. Optom Vis Sci 2015;92:471-479.

92. Beebe DC, Holekamp NM, Shui YB. Oxidative damage and the prevention of age-related cataracts. Ophthalmic Res 2010;44:155-165.

93. Zeng J, Borchman D, Paterson CA. Acute effect of ethanol on lens cation homeostasis. A/cohol 1998;16:189-193.

94. Oh JY, Yu JM, Ko JH. Analysis of ethanol effects on corneal epithelium. Invest Ophthalmol Vis Sci 2013;54:38523856.

95. Liu H-Y, Yeh P-T, Kuo K-T, Huang J-Y, Lin C-P, Hou Y-C. Toxic keratopathy following the use of alcohol-containing antiseptics in nonocular surgery. JAMA Ophthalmol 2016;134:449-452.

96. Kim JH, Kim JH, Nam WH, Yi K, Choi DG, Hyon JY, et al. Oral alcohol administration disturbs tear film and ocular surface. Ophthalmology 2012;119:965-971.

97. Chia EM, Mitchell P, Rochtchina E, Lee AJ, Maroun R, Wang $J J$. Prevalence and associations of dry eye syndrome in an older population: the Blue Mountains Eye Study. Clin Exp Ophthalmol 2003;31:229-232.

98. Galor A, Feuer W, Lee DJ, Florez H, Faler AL, Zann $\mathrm{KL}$, et al. Depression, post-traumatic stress disorder, and dry eye syndrome: a study utilizing the national United States Veterans Affairs administrative database. Am J Ophthalmol 2012;154:340-346.e342.

99. Moss SE, Klein R, Klein BE. Prevalence of and risk factors for dry eye syndrome. Arch Ophthalmol 2000;118:12641268.

100. Cumurcu T, Gunduz A, Cumurcu BE, Gül IG, Akpolat N, Karlidag R. The changes in tear film parameters and impression cytology in heavily drinking men. Cornea 2013;32:237-241.

101. Lu P, Chen X, Liu X, Yu L, Kang Y, Xie Q, et al. Dry eye syndrome in elderly Tibetans at high altitude: a populationbased study in China. Cornea 2008;27:545-551.

102. Viso E, Rodriguez-Ares MT, Gude F. Prevalence of and associated factors for dry eye in a Spanish adult population (the Salnes Eye Study). Ophthalmic Epidemiol 2009;16:1521.

103. Xu L, You QS, Jonas JB. Prevalence of alcohol consumption and risk of ocular diseases in a general population: the Beijing Eye Study. Ophthalmology 2009;116:1872-1879.

104. You YS, Qu NB, Yu XN. Alcohol consumption and dry eye 
syndrome: a meta-analysis. Int J Ophthalmo/ 2016;9:14871492.

105. Oh JY, Yu JM, Ko JH. Analysis of ethanol effects on corneal epithelium. Invest Ophthalmol Vis Sci 2013;54:38523856.

106. Cumurcu T, Gunduz A, Cumurcu BE, Gul IG, Akpolat $\mathrm{N}$, Karlidag $\mathrm{R}$. The changes in tear film parameters and impression cytology in heavily drinking men. Cornea 2013;32:237-241.

107. Lieber CS. Alcohol, liver, and nutrition. J Am Coll Nutr 1991;10:602-632.

108. Hatchell DL, Sommer A. Detection of ocular surface abnormalities in experimental vitamin A deficiency. Arch Ophthalmol 1984;102:1389-1393. 